\title{
Os limites das capitanias hereditárias do sul e o conceito de território
}

Jorge Pimentel Cintra ${ }^{1}$

RESUMO: Analisam-se os limites das capitanias do sul (1534-1700), chegando a interessantes conclusões. As terras da Capitania de Santana, em função da estimativa que se faça para a longitude de Tordesilhas, ou pertenciam à Espanha ou formavam pequenas parcelas descontínuas. $\bigcirc$ limite norte da Capitania de São Tomé (Pero de Góis), definido por acordo entre os dois confrontantes, afetava um terceiro território, coisa que não se percebeu. $\bigcirc$ limite sul dessa capitania na carta de doação indicava uma linha correndo diretamente para oeste, enquanto que na de seu vizinho (Martim Afonso) indicava uma linha correndo a noroeste. Essa mesma direção também está definida para o limite sul desse lote, complicando a partição das terras. Essas fronteiras artificiais nunca foram demarcadas nem tidas em conta, e tanto os donatários como a Coroa foram criando vilas e cidades em terreno alheio: umas vezes por não levar em conta os limites das cartas de doação (São Paulo, Santana de Parnaíba, Mogi das Cruzes, São Sebastião, Taubaté, Paranaguá, por exemplo); outras por ocupação indevida, mas necessária (Rio de Janeiro); por dolo ou extrapolação de poderes (Cabo Frio); ou mesmo em terras de Castela (Curitiba). A isso veio somar-se a questão de jurisdição sobre a Capitania de Santo Amaro (a querela entre as casas de Monsanto e Vimieiro); a questão da extrapolação de jurisdição (Angra dos Reis e Paraty); e finalmente a má-fé e as tropelias de juízes, capitães-gerais e da Coroa. $\bigcirc$ entendimento dessas questões, facilitada pela cartografia histórica, permitiu revelar pontos desconhecidos da história das capitanias, explicar melhor a formação dos limites dos atuais Estados e aprofundar-se no entendimento dos conceitos da época para indicar o território: termo, sertões, fundos e outros.

PALAVRAS-CHAVE: Capitanias hereditárias. Limites entre as capitanias hereditárias. Capitania de São Vicente. Limites do Rio de Janeiro. As capitanias e seu território.

ABSTRACT: We analyze the limits of the southern Captaincies (1534-1700), reaching interesting conclusions. The Terras de Santana Captaincy, depending on the estimate of the longitude of the Tordesillas line, or belonged to Spain or are formed by small discrete portions. The northern limit of the Captaincy of São Tomé (Pero de Gois) defined by agreement between the two
1. Docente da Escola Politécnica da USP. E-mail: <jpcintra@usp.br>. 
neighbors affected a third territory, something that was not perceived. The southern boundary of this Captaincy in the Donation Letter indicated a line running directly to the west, while in his neighbor Letter (Martim Afonso) indicated a line running northwest. This same direction is also set to the southern limit of that lot, complicating the partition of the lands. These artificial boundaries have never been demarcated or taken into account, and both the donatories, as the crown, were creating towns and cities in foreign land: sometimes for not taking into account the limits of the Donation Letters (São Paulo, Santana de Parnaiba, Mogi das Cruzes, São Sebastião, Taubaté, Paranaguá, for example); others by improper occupation, even when necessary (Rio de Janeiro); intentionally or extrapolation of powers (Cabo Frio); or even in the land of Castile (Curitiba). To this has added up the question of jurisdiction over the Captaincy of Santo Amaro (the quarrel between the houses of Monsanto and Vimieiro); the question of extrapolation jurisdiction (Angra dos Reis and Paratyl and finally the bad faith and mischief of judges, general captains and the crown. The understanding of these issues, facilitated by historical cartography, allows us to understand unknown point of the history of the captaincies; a better explain of the formation of the limits of current States and a deeper the understanding of the concepts of that time to indicate the territory: termo, sertão (hinterlands), fundos (funds) and others.

KEYWORDS: Hereditary Captaincies. Borders between the Hereditary Captaincy. Captaincy of São Vicente. Limits of the Rio de Janeiro State. The Captaincies and their territory.

\section{Introdução}

Em trabalho anterior, ${ }^{2}$ mostramos que as divisas clássicas das capitanias hereditárias estavam equivocadas, desde a sua propositura por Varnhagen, em 1854. A nova proposta, baseada em fontes primárias (cartas de doação, mapas e outros documentos), pode ser resumida visualmente na Figura 1.

As principais mudanças com relação à proposta de Varnhagen ao norte são a existência de terras não distribuídas na região dos atuais estados do Pará e Maranhão e as linhas divisórias, que correm segundo meridianos e não paralelos, para todas as capitanias acima da de ltamaracá. Já ao sul, as principais mudanças decorrem da definição dos limites do primeiro lote de Martim Afonso (São Vicente 1), contendo linhas com a direção noroeste até encontrar determinado paralelo $\left(21^{\circ}\right.$ e $\left.23^{\circ}\right)$, com impacto nas capitanias vizinhas: São Tomé, que assume uma forma triangular, e Santo Amaro. Esse mapa constitui-se numa visão geral das divisões e, pela escala do mesmo, não é possível apreciar alguns detalhes, coisa que exige uma escala maior.

Assim, no presente trabalho, examina-se o mapa em escala de maior detalhe e inferem-se algumas consequências desse novo desenho, analisando com maior profundidade os limites das capitanias do sul: São Tomé, São Vicente, Santo Amaro e Santana, mostrando os conflitos teóricos e práticos que ocorreram, incluindo a criação de vilas e cidades em terras alheias, e como isso ajuda a explicar melhor os limites atuais do estado de São Paulo, do Rio de Janeiro e do Espírito Santo. 


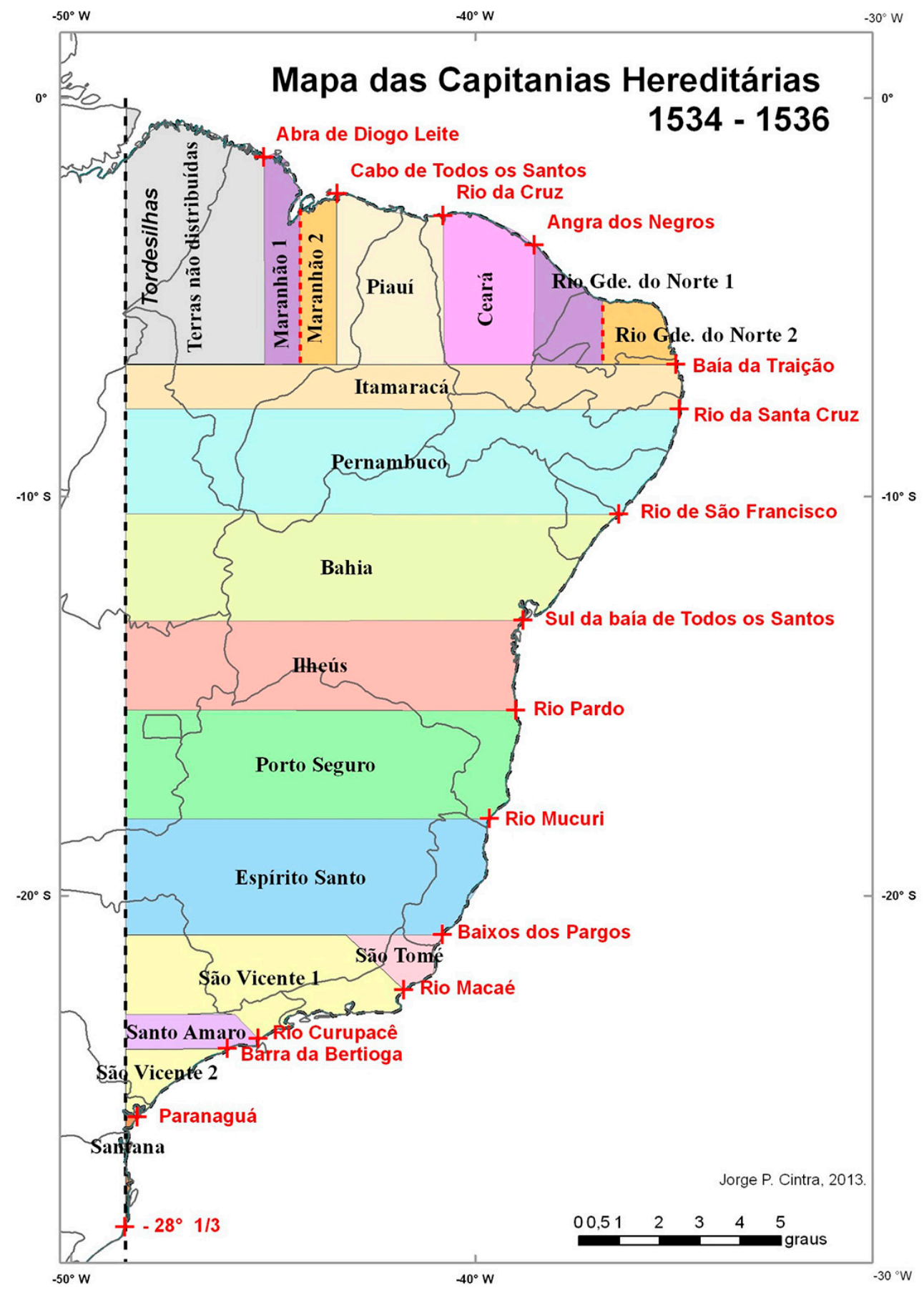

Figura 1 - Desenho das capitanias hereditárias com seus limites. Fonte: Cintra (2013).

Iniciamos essa análise pelas questões mais simples, como a de Santana, passamos pelas mais complexas, incluindo os embates entre as casas de Monsanto e Vimieiro, e concluímos com o exame da noção de termo de uma vila, fundamental para entender algumas questões. 
3. Cintra (2012).

3. Cintra (2012)

Como se lê na correspondente carta de doação, Pero Lopes de Sousa recebeu 80 léguas de terra: 30 ao norte na Capitania de ltamaracá e 50 ao sul, divididas estas em dois lotes: 10 léguas da capitania que se chamou posteriormente de Santo Amaro, encravada nos lotes de Martim Afonso, e as 40 restantes nas chamadas Terras de Santana.

Estas começavam num ponto situado a 12 léguas ao sul da lha de Cananeia, que corresponde aproximadamente à llha do Mel ou à barra sul da Baía de Paranaguá, e findavam no que se considerava o limite meridional das terras portuguesas: a latitude de $28^{\circ} 1 / 3$.

A Figura 2 mostra a situação e permite algumas análises.

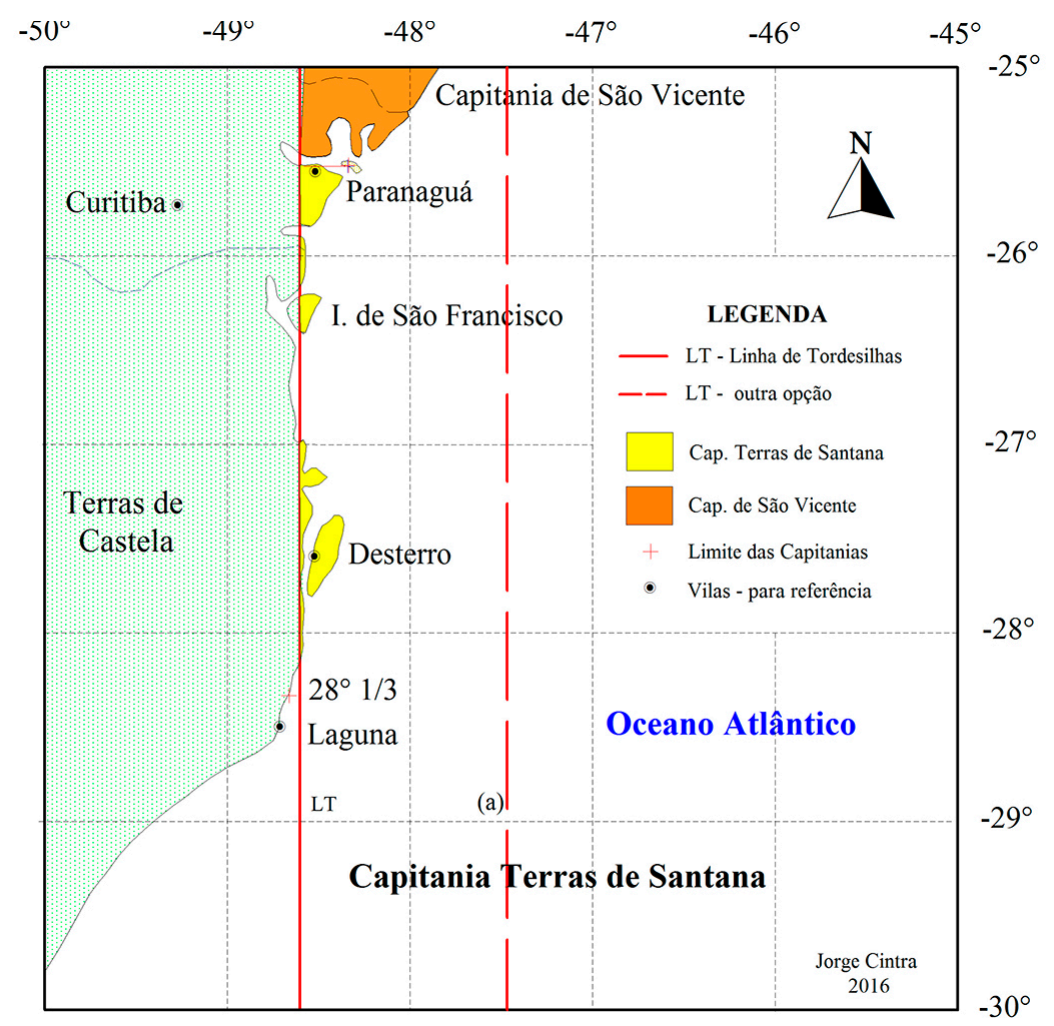

Figura 2 - Peculiares limites da Capitania de Santana. Fonte: o autor.

Em outro trabalho, ${ }^{3}$ calculamos as duas longitudes mais prováveis para a Linha de Tordesilhas: $48^{\circ} 35^{\prime}$ e $47^{\circ} 28^{\prime}$. Na Figura 2, a linha desenhada em vermelho sólido (LT) corresponde ao primeiro valor e recortaria a costa brasileira, nesse território, desde um ponto na Baía de Paranaguá até outro, um pouco ao sul do paralelo $28^{\circ}$, sem chegar aos $28^{\circ} 1 / 3$ e, o que é peculiar, forma uma capitania descontínua, representada em amarelo nessa figura. Isso caracteriza a posse de pequenos trechos da costa, da lha de Florianópolis e de parte da llha de São 
Francisco, deixando nas regiões intermediárias diversos trechos da costa dentro dos domínios castelhanos, com saída para o mar. Teoricamente isso inviabilizaria a ocupação e cultivo dessas terras que formavam 5 ou 6 porções isoladas. $\mathrm{Na}$ prática, inexistindo a demarcação, isso não impediu a ocupação dessa costa nem a fundação de Curitiba, já em terras de Castela.

Nessa figura foi desenhada também, em vermelho tracejado, a segunda alternativa (a) dessa linha $\left(47^{\circ} 28^{\prime}\right)$ e, nessa variante, a Capitania de Santana simplesmente não existiria, tendo D. João III distribuído terras que não the pertenciam.

Nos livros didáticos, umas vezes se dá por certo que a Linha de Tordesilhas corre por Laguna (na altura de $28^{\circ}$ 1/3), o que só é válido grosso modo; outras vezes se desloca esse meridiano para o interior do continente, talvez para mostrar umas terras contínuas e fáceis de visualizar em um mapa de escala pequena.

Na época, diga-se de passagem, e até bastante tempo depois, não se dispunha de uma técnica para medir com precisão a latitude lo erro se situava na casa de $1 / 3$ de grau) e muito menos a longitude (erro superior a $1^{\circ}$ ou mesmo $2^{\circ}$ ), de tal forma que se pode dizer que a fixação do limite num ponto com latitude de $28^{\circ} 1 / 3$ foi uma aproximação muito boa.

\section{A Capitania de São Tomé e seus limites conflitantes}

limite norte da Capitania de São Tomé (de Pero de Góis) coincide com - limite sul da Capitania do Espírito Santo (de Vasco Fernandes Coutinho). A carta de doação dessa última não estabelece nenhum topônimo para esse limite, indicando que se situa onde acabam as 50 léguas desse donatário, medidas a partir do limite ao norte. Isso aconteceu porque a divisão havia começado pelo Rio de Santa Cruz (Pernambuco, Figura 1) e veio somando léguas para o sul. Já a carta de doação de São Tomé, que resultava de uma divisão vinda do sul, indica como limite norte os "Baixos de Pargos", ou seja, os baixios onde se pescava esse tipo de peixe.

O local já aparece no conhecido mapa Terra Brasilis (1519), com essa denominação no interior junto à costa, acrescido de a pescaria dos pargos, grafada no Atlântico. Fizemos uma representação desse local na Figura 3, que aparece hachurado no Atlântico, acima e abaixo do paralelo $21^{\circ}$ (S). Por sua própria natureza, trata-se de local dilatado e impreciso (com cerca de $1^{\circ}$ de extensãol e por isso os dois confrontantes, a 12 de março de 1543, acertaram que os terrenos "partem ambos por um rio chamado, na língua dos índios, Tapemery [ltapemirim], que os mesmos puseram o nome de Santa Catarina [em homenagem à esposa de D. João III], ficando todo o dito rio com Pero de Góis para a banda do sul e o dito Vasco Fernandes da banda do rio para a parte do norte" ${ }^{4}$

Mas esse documento de acerto, conquanto fixe o ponto na costa, não se preocupou por dizer o que aconteceria com a linha divisória no interior do continente. Aliás, as duas cartas de doação dizem simplesmente que as "léguas se estenderão e serão de largo ao longo da costa e entrarão na mesma largura pelo 
5. Cintra (2015).

6. Lamego (s.d., p. 46). sertão e terra firme adentro, tanto quanto puderem entrar e for de minha conquista". Ou seja, não falam de uma linha correndo para oeste; um paralelo, em linguagem cartográfica. No entanto, essa forma geométrica é a que se deduz tendo em conta um mapa geral das capitanias, como o conhecido mapa de Luis Teixeira, ${ }^{5}$ ou alternativamente o conjunto escrito das cartas de doação, pois em duas delas se fala de uma linha correndo para oeste, e a cláusula da mesma largura (constante) pelo sertão obriga o paralelismo entre elas. Mas como os donatários não tinham acesso a um mapa nem às cartas dos demais, o mais natural, como se procura mostrar, é que tivessem entendido esses limites como certa quantidade de léguas na costa, com um território entrando pelo sertão adentro, sem uma definição mais precisa das linhas divisórias. Em resumo, o território seria a costa e seu sertão, ficando o problema dos limites no interior relegado a um segundo momento, mesmo porque as terras eram abundantes e as preocupações prioritárias eram o cultivo da marinha e a sobrevivência aos ataques indígenas.

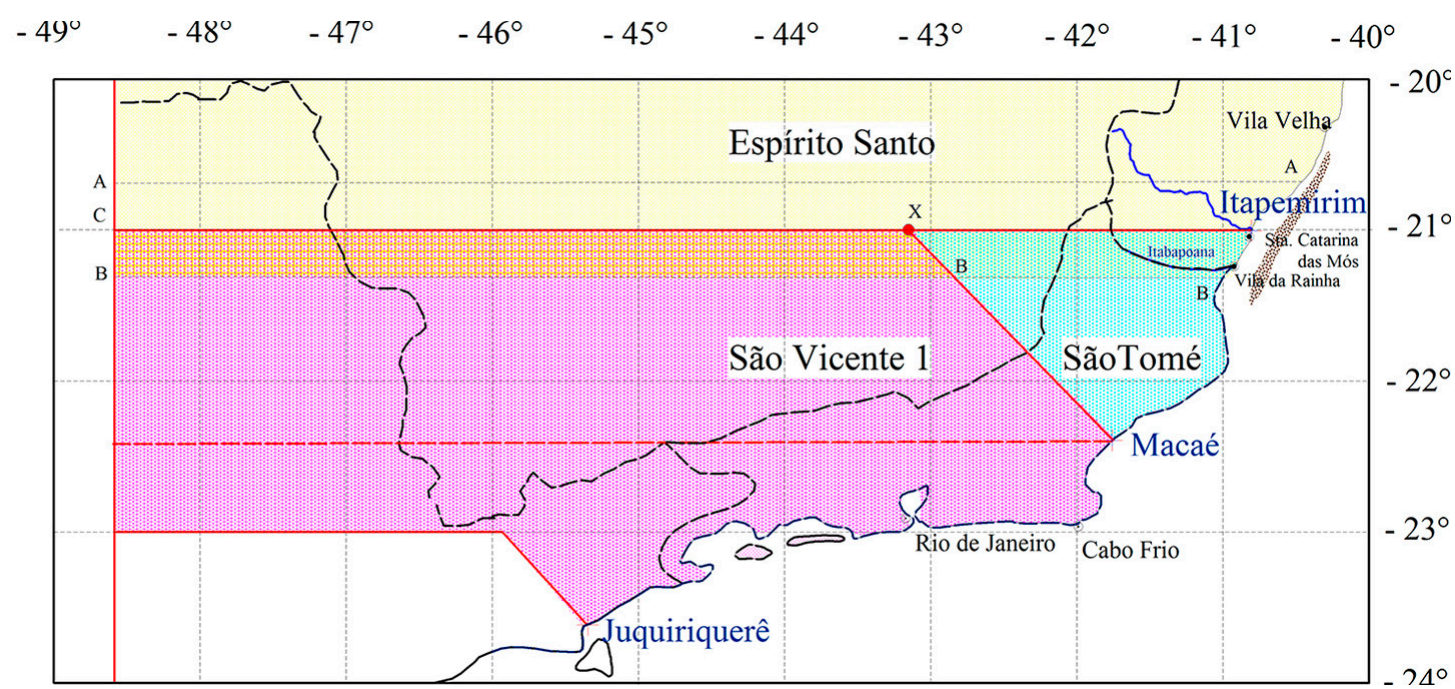

Figura 3 - As linhas divisórias de São Tomé e de São Vicente (lote 1). Fonte: o autor.

O donatário de São Tomé criou a Vila da Rainha loutra homenagem a D. Catarina), na foz do rio Managé (hoje Itabapoana), e não na barra do Paraíba do Sul, conforme esclareceu Lamego, ${ }^{\circ}$ corrigindo Varnhagen. E depois de ser essa vila destruída pelos índios, levantou outra do mesmo nome oito léguas rio acima, ao pé da cachoeira do Inferno. Após sua morte, Gil de Góis (filho e sucessor) ergueu nova vila, Santa Catarina das Mós (moendas de engenho) em frente ao Baixo dos Pargos, ao sul do rio Itapemirim. Este, para todos os efeitos, passou a representar a fronteira das capitanias, seguindo, portanto, uma divisa tortuosa correndo de sudeste a noroeste (Figura 3), abandonando o retilíneo e imaginário paralelo de divisa. Apesar do muito esforço, esse novo donatário, por falta de recursos, acabou renunciando à capitania em favor da Coroa, que por sua vez faria mais tarde uma distribuição dessas terras às capitanias vizinhas. 
Mas se a carta de Pero de Góis não define bem as fronteiras, a de Martim Afonso é clara e precisa nos dois pontos limites, dizendo o texto ao norte e ao sul: "se porá um padrão das minhas armas [um marco físico], e se lançará uma linha pelo rumo noroeste até a altura de $\left[21^{\circ}\right.$ na primeira linha e $23^{\circ}$ na segunda] e desta dita altura se lançará outra linha, que corra [ou corte] diretamente para oeste". Ou seja, não só se materializam os pontos limítrofes como se explicitam os rumos que as linhas divisórias deviam seguir. ${ }^{7}$

Com essas linhas inclinadas a $45^{\circ}$ (noroeste, Figura 3), surgem alguns conflitos. $\bigcirc$ primeiro deles é a oposição dos textos das cartas de doação no referente à linha que parte de Macaé: ela corre segundo um paralelo em direção a Tordesilhas (na carta de Pero de Góis, linha tracejada na Figura 3) ou segue o rumo de noroeste (vermelho contínuo na de Martim Afonso)? Está em jogo uma ampla faixa que abrange parte não desprezível dos atuais estados do Rio de Janeiro, Minas Gerais e São Paulo. Essa faixa situa-se entre o paralelo $21^{\circ}$ a partir do ponto X dessa figura e o paralelo de Macaé $\left(22,38^{\circ}\right)$, incluindo as atuais terras de Juiz de Fora, Barbacena, São João del Rei, Ribeirão Preto e São Carlos, para citar só algumas cidades. Parece-nos que, numa improvável discussão de limites, prevaleceria a definição da carta de doação de Martim Afonso, ou seja, a linha inclinada. Essa situação que adotamos cria um problema envolvendo os três donatários que se confrontam no ponto X (Figura 3). $\bigcirc$ conflito se dá porque a carta de Martim Afonso indica que a partir do ponto X a divisa segue pelo paralelo $21^{\circ}$ e os dois outros confrontantes acordaram implicitamente que a linha seguiria pelo (paralelo do) rio Itapemirim, sem considerarem a latitude desse ponto. Essa definição poderia criar duas geometrias diferentes (ainda na Figura 3) em função de o meridiano de Itapemirim situar-se acima (posição AA) ou abaixo (posição BB) do paralelo $21^{\circ}$.

Na situação AA, com o rio acima do paralelo $21^{\circ}$, a Capitania de São Tomé ganharia uma faixa de terra entre os paralelos de Itapemirim /considerado em $A A)$ e $\circ 21^{\circ}$. Já na situação BB, situando-se o rio ltapemirim abaixo do paralelo $21^{\circ}$ (que é a situação de fato), cria-se um conflito de terra, com uma faixa (polígono BBCX) que poderia ser reclamada por Martim Afonso e, mesmo que sem razão, pelo donatário da capitania do Espírito Santo. Mas como a latitude do rio Itapemirim é 21,005\% , isso torna a largura dessa faixa desprezível, cerca de 500 $\mathrm{m}$, diferença que não seria detectada na época. $\bigcirc$ conflito existe somente no plano teórico, por causa de uma definição de limites conflitante. Na prática ninguém atentou para isso, nem houve preocupação de demarcar essas linhas no terreno.

Com o transpasse à Coroa, essas terras de São Tomé, junto com outras ao sul do país, foram doadas mais tarde (1674), como capitanias hereditárias aos filhos de Salvador Correia de Sá, ${ }^{8}$ ou seja, a Martim Correia de Sá (I Visconde de Asseca) e a seu irmão, João Correia de Sá. Na partilha feita tempos mais tarde, essa capitania foi dividida em 2 quinhões nessa região: João Correia de Sá ficou com as 5 léguas entre o rio Itapemirim e o rio Itabapoana, enquanto o filho de Martim Correia de Sá (este já falecido) ficou com as 20 léguas entre esse rio e o
7. Para o outro lote desse donatário, a situação é semelhante: colocar marcos e traçar as linhas, correndo agora para o oeste.

8. Lamego (s.d., p. 47). 
9. A última vila foi criada em 1675 e a seguinte seria criada em 1701. Esse fim de período corresponde à época em que a Coroa aumentou fortemente seu controle e intervenção sobre todas as capitanias. Há mais 13 vilas nesse território fundadas entre 1701 e 1800.

10. Cintra (2015, p. 38-39). Por não ter em conta essa diferenciação, Varnhagen (1956, v II, p. 34) sentiu estranheza ao tratar da fundação de São Cristóvão do rio de Sergipe em 1590:

"[Cristóvão de Barros] fundou um verdadeiro arraial, a que já deu o nome de cidade". Assim, pequenos núcleos já nascem como cidades; outros exemplos são Filipeia de Nossa Senhora das Neves e Cabo Frio, e o próprio Rio de Janeiro, que nasce cidade, sem haver povoação anterior. Esse choque cognitivo é interessante para detectar de Macaé (Figura 3, novamente). No século XVIII a Coroa retoma essas terras e faz a incorporação da primeira parcela à Capitania do Espírito Santo e a segunda à do Rio de Janeiro; o que explica a fronteira atual entre os dois estados. Como se vê, prevaleceu a divisão por fronteiras naturais (rio Itabapoana) e não os paralelos geométricos.

4 A apropriação real do território do Rio de Janeiro

Sobre a fronteira sul do primeiro lote de São Vicente não houve dúvidas ao longo da história: ela começava no rio Curparê, Curupacê ou Curupacé, depois e até hoje denominado Juquiriquerê. Nesse território, os sucessores de Martim Afonso, por si ou seus procuradores, foram criando vilas.

Para entender as diversas questões que surgem, montamos a Tabela 1. Nela figuram as 20 vilas e 2 cidades criadas entre 1532 e 1700 nesse território. ${ }^{9}$ A divisão em vilas e cidades (Rio de Janeiro e Cabo Frio) não se deve a um critério de hierarquia, mas ao fato de serem criadas pelo donatário ou diretamente pela Coroa, como se explica em Cintra. ${ }^{10}$

Tabela 1 - Povoações criadas de 1532 a 1700 nas capitanias de Martim Afonso e de seu irmão

\begin{tabular}{|c|c|c|c|}
\hline$N^{\circ}$ & VILA / CIDADE & DATA & DOCUMENTO \\
\hline 1 & São Vicente & 1532 & carta régia \\
\hline 2 & Santos & 1545 & foral \\
\hline 3 & São Paulo & 1558 & foral \\
\hline 4 & Itanhaém & 1561 & foral \\
\hline 5 & Rio de Janeiro & 1567 & criação de fato \\
\hline 6 & Cananeia & 1600 & provisão \\
\hline 7 & Angra dos Reis & 1608 & foral \\
\hline 8 & Mogi das Cruzes & 1611 & provisão \\
\hline 9 & Cabo Frio & 1615 & criação de fato \\
\hline 10 & Santana de Parnaíba & 1625 & provisão \\
\hline 11 & lguape & 1635 & foral \\
\hline 12 & São Sebastião & 1636 & provisão \\
\hline 13 & Ubatuba & 1637 & provisão \\
\hline
\end{tabular}




\begin{tabular}{|c|c|c|c|}
\hline No & VILA / CIDADE & DATA & DOCUMENTO \\
\hline 14 & Taubaté & 1645 & provisão \\
\hline 15 & Paranaguá & 1648 & carta régia \\
\hline 16 & Guaratinguetá & 1651 & foral \\
\hline 17 & Jacareí & 1653 & foral \\
\hline 18 & Jundiaí & 1655 & provisão \\
\hline 19 & Itu & 1657 & provisão \\
\hline 20 & Sorocaba & 1661 & provisão \\
\hline 21 & Paraty & 1667 & carta régia \\
\hline 22 & Curitiba & 1675 & foral \\
\hline
\end{tabular}

As datas de criação apoiam-se no trabalho de Machado Junior ${ }^{11}$ e foram completadas e conferidas com as obras clássicas de Frei Gaspar (1797)12 e Pedro Taques (1772). ${ }^{13}$ Quando não se tem certeza sobre o tipo de documento, grafamos em itálico. São 6 povoações até 1600 e 16 de 1601 a 1700. As datas consideradas referem-se à elevação de povoação (ou freguesia) à vila ou à criação direta como vila ou cidade. Isso se fazia, nesse período, mediante carta régia, foral ou provisão. ${ }^{14}$

No primeiro lote de Martim Afonso foram criadas: Rio de Janeiro (1567), Angra dos Reis (1608), Cabo Frio (1615), Ubatuba (1637), Taubaté (1645), Guaratinguetá ( 1651 ) e Paraty (1667). Como se mostrou em outro trabalho (CINTRA, $20161,{ }^{15}$ o Rio de Janeiro foi criado em situação emergencial, em terreno alheio, para reconquistar essa posição aos franceses e índios aliados a eles. A Coroa não desapropriou essas terras, mas a fundação da cidade contou com o consentimento implícito do rei e mais tarde do donatário. Por sua vez, a cidade de Cabo Frio foi criada sem o consentimento da Coroa. Esta solicitou a ocupação das terras, para consolidar a posição conquistada, mas não deu ordem de criar uma cidade. ${ }^{16}$

Iniciou-se assim a ocupação de fato desse território pela Coroa e criou-se uma dupla jurisdição, que se manifesta, entre outras coisas, pelas doações de terras. Assim, o representante do governador do Rio de Janeiro, Estevão Gomes, sem autoridade para isso, fixa arbitrariamente o termo ${ }^{17}$ de Cabo Frio para o norte até o rio Macaé ( 13 léguas), e para o sul até o primeiro local habitado por pessoas vindas do Rio de Janeiro. Começa assim o apossamento desse território de Martim Afonso até terminar com sua incorporação de fato à Coroa, como se detalha em Cintra. ${ }^{18}$

Para isso contribuiu decisivamente o fato de esse representante distribuir diversas sesmarias, entre elas, a seus parentes, a si próprio, aos jesuítas e aos beneditinos do Rio de Janeiro. Essas duas ordens religiosas, depois de intensos debates, aperceberam-se da nulidade dessas doações e solicitaram confirmação de suas datas ao capitão loco-tenente do legítimo donatário, sucessor de Martim diferenças de conceitos ou de imaginários entre épocas.

11. Machado Junior (2011).

12. Madre de Deus (1975).

13. Leme (2004).

14. Mantivemos para São Paulo a data indicada por Machado Junior (2011), que corresponderia a um foral de Mem de Sá, de 5/9/1558, ainda que a transferência do pelourinho de Santo André (da Borda do Campo) parece ter-se dado em 1560 (segundo Pedro Taques, Frei Gaspar e muitos outros). Por outro lado, a data convencional é a da missa dos jesuítas a 25/1/1554. É questão mais ampla e nos levaria muito longe.

15. Cintra (2016).

16. O emprego desse termo e categoria, cidade, foi um subterfúgio para não conflitar com o poder de criar vilas, que competia ao donatário.

17. Conceito fundamental na época, equivalente 
aproximadamente ao nosso de território a que se estende a jurisdição da câmara.

18. Cintra (2016).

19. Em 1623, os jesuítas, através do seu reitor João de Oliva, pediram terras no Cabo Frio ao capitão-mor loco-tenente da donatária condessa de Vimieiro, dizendo na súplica: que suposto as terras que pediam já as possuíam por carta de sesmaria de Estevão Gomes (...) se havia reconhecido que o dito Estevão Gomes não tinha jurisdição para conceder terras, cujo poder só residia nos capitães-mores governadores da capitania de São Vicente. Semelhante requerimento fizeram os monges beneditinos. Leme (2004, p. 118).
Afonso nessas terras. ${ }^{19} \bigcirc$ próprio Estevão Gomes recorreu a esse capitão, suplicando-the sesmarias nessas terras de Cabo Frio, "depois de ver os fundamentos com que os jesuítas mostraram que eram nulas as concedidas por ele". ${ }^{20}$

Mas como nem todos se aperceberam dessa falta de jurisdição instalouse a confusão, com uma dupla jurisdição, tanto no Cabo Frio como no Rio de Janeiro. Os capitães-mores de São Vicente, por sua vez, continuaram a distribuir sesmarias e datas de chãos, inclusive no coração do Rio de Janeiro: junto ao Pão de Açúcar e ao Largo da Carioca, dentro do rocio da cidade, como salientam Madre de Deus ${ }^{21}$ e Taques. ${ }^{22}$

Por sua vez, Angra dos Reis foi criada pelo donatário e Paraty desmembrada da primeira com confirmação régia. Essas duas vilas dependiam de São Vicente quanto ao regime tributário, à distribuição de terras (sesmarias) e também quanto à jurisdição no cível e no crime. Em função da distância à cabeça da capitania, essas vilas solicitaram a transferência somente dessa última jurisdição para o Rio de Janeiro, no que foram atendidas, e isso foi também a causa do crescente e indevido aumento de jurisdição por parte da Coroa.

Com a descoberta das minas de ouro, a partir de 1693, o rei concedeu aos governadores do Rio de Janeiro a Superintendência das Minas no Sertão do Brasil, e submeteu a eles todos os governadores, capitães e justiças dos donatários, nas matérias das minas e nas questões de guerra, se se apresentassem. Isso foi uma porta aberta para que na prática a jurisdição fosse se ampliando para todos os âmbitos. Até 1773 os donatários continuaram a distribuir terras e a receber a dízima ou redízima dos produtos, mas sua autoridade vai-se reduzindo. Para efeitos práticos, a Coroa leva o extremo do território do Rio de Janeiro até os confins de Paraty, avançando sobre o território de Martim Afonso e definindo assim as divisas com São Paulo. Não houve compra do território pela Coroa, mas só uma compensação muito tardia, já no reinado de D. Maria I.

\section{Os limites entre São Vicente e Santo Amaro ao longo da costa}

Os pontos limites da Capitania de Santo Amaro estão claros na carta de doação: rio Juquiriquerê ao norte, e a barra da banda do norte do rio de São Vicente (barra da Bertioga) ao sul. A questão pode ser mais bem entendida através da Figura 4 , onde se veem as 3 barras a respeito das quais surgiram as controvérsias.

Por essa figura se vê que no lagamar dessa região encontram-se duas ilhas, a de São Vicente, onde se situavam duas vilas: São Vicente e Santos; e a itha de Santo Amaro (ou Guaimbé, como a chamavam os antigos), onde hoje se situa o Guarujá, mas na época não havia vila alguma. Formam-se assim três bocas, indicadas nessa figura pelos números 1, 2 e 3. A primeira mais ao norte, conhecida hoje como barra da Bertioga, a segunda como barra de Santos e a terceira como de São Vicente. Mas na época todas eram barras do que eles chamavam rio de São Vicente: o conjunto de água doce formado por alguns rios e que é invadido 
pelas águas do mar. Por isso, a carta de Martim Afonso e a de Pero Lopes falam do rio de São Vicente, acrescentando a expressão barra da banda do norte para indicar a de Bertioga e distinguila das demais.

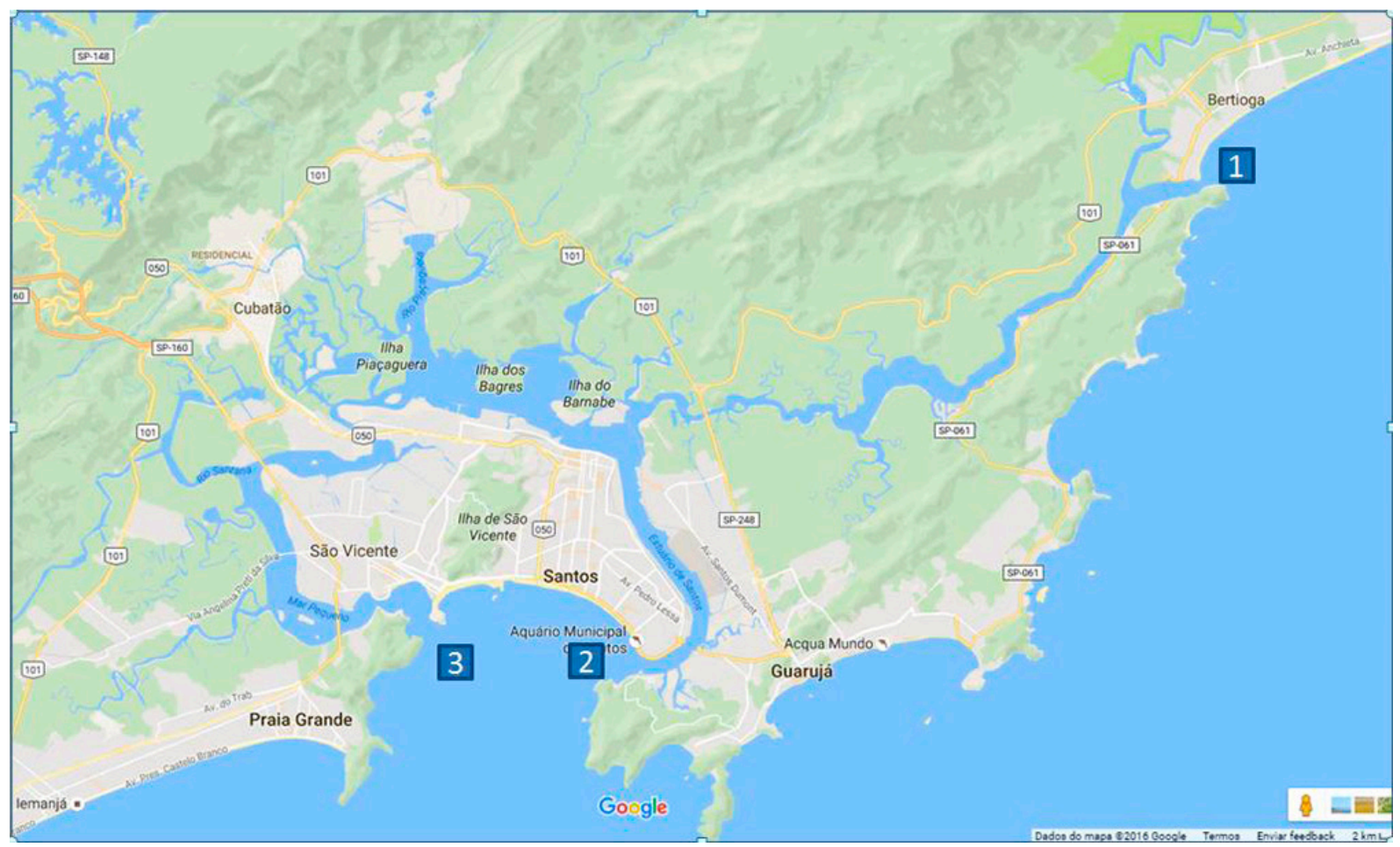

Figura 4 - As 3 barras, motivo de confusão: 1 - Bertioga, 2 - Santos, 3 - São Vicente. Fonte: modificado pelo autor a partir do Google Maps.

A segunda itha, em terras de Martim Afonso, tomou o nome de Guaimbé e depois Santo Amaro, em função de uma ermida dedicada a esse santo, erigida nessas terras.

Pero Lopes e seus herdeiros não fundaram nenhuma cidade em suas terras do sul, e seus representantes, residentes em Santos, distribuíram, corretamente, terras em sesmarias para além da barra da Bertioga e até o rio Juquiriquerê. Aconteceu que uns sesmeiros, querendo subtrair-se à jurisdição de Martim Afonso, atribuíram-se estar sob a jurisdição de seu irmão Pero Lopes. Apesar de contestados, a confusão prevaleceu, a ponto de a Capitania de Pero Lopes tomar o nome dessa itha de Martim Afonso e de deslocar-se a divisa, na prática, para a barra de Santos, ainda que muitos possuidores de terras solicitassem confirmação aos dois donatários.

A essa problemática soma-se a questão Monsanto-Vimiero, que se resume assim: D. Izabel de Lima de Sousa e Miranda, neta de Pero Lopes de Souza e herdeira única, falecendo sem descendentes, deixou todos os lotes lltamaracá, Santo Amaro e Santana) em testamento a Lopo de Souza, neto de Martim Afonso e seu primo em segundo grau. No entanto, D. Luis de Castro, conde de Monsanto, também neto de Martim Afonso, contestou a validez desse testamento, pois estaria 
20. Madre de Deus (1780, p. 15).

21. Madre de Deus (1780, p. 11). contrariando a lei de sucessão das capitanias hereditárias, especificada na própria carta de doação. Ao morrer lopo de Souza sem sucessores, as terras foram herdadas por sua irmã, D. Mariana de Souza Guerra, condessa de Vimieiro. A questão arrastou-se por diversas gerações até o início do século XVIII, com ganho de causa para um e outro lado, provocando grande confusão quanto ao legítimo dono das terras, que, ao que tudo indica, era o Conde de Monsanto. Mas só quanto às terras de ltamaracá, Santo Amaro e Santana, e não às de São Vicente, em seus dois lotes.

No auge da controvérsia pelo limite dessas capitanias, por volta de 1620, houve ações fraudulentas que forçaram, contra todo o direito, a colocação do marco divisório (Santo Amaro/São Vicente) na terceira barra, ao sul da cidade de São Vicente. As autoridades foram coniventes com essa clamorosa injustiça que só foi reparada no reinado de D. Maria I, no fim do século XVIII. Diante das injustiças, Frei Gaspar discorre apaixonadamente, com muitos argumentos, para mostrar que o limite era pela barra da Bertioga. Dentre esses, destacamos somente um: o fato de serem 10 as léguas de Pero Lopes de Sousa, a partir do rio Juquiriquerê, segundo a carta de doação.

Isso se prova medindo as léguas, sobre um mapa atual, com o auxilio de um programa de cartografia digital (Maplnfo, por exemplo). Resulta no valor de 14 léguas. ${ }^{23}$ Isso concorda com o depoimento de 10 pilotos, experimentados nesse trecho da costa, que foram chamados para testemunharem no caso. Afirmaram unanimemente e em altas vozes que nesse trecho se encontravam 12 léguas esforçadas (com sobra), talvez 13. E que até a barra ao sul de São Vicente haveria mais 5 ou $6 .{ }^{24}$

Por disputas de terra, falsificaram-se as cartas de Pero Lopes para excluir do texto a expressão da banda do norte, e assim forçar a interpretação de que a barra do rio de São Vicente ficava junto à vila desse nome.

Foram com muita probabilidade os partidários da causa de Monsanto que adulteraram as cópias da carta de doação de Pero Lopes de Sousa para alterar as léguas de 10 para 12 e de suprimir a expressão da banda do norte, justaposta à barra de São Vicente, para forçar a demarcação mais ao sul. Mas a carta de doação de Martim Afonso, na qual se pode conferir as expressões da fronteira, não foram adulteradas. Além disso, se fossem 12 as léguas de Pero Lopes, a soma com as 40 ao sul de Paranaguá (não adulteradas) daria 52 e não 50 léguas como indica a carta de doação a Pero Lopes.

Como se não bastasse isso, o procurador da Fazenda, representante da Coroa, Fernão Vieira Tavares, que deveria ser árbitro na questão, serviu-se de prepotência, por despeito pessoal; sem efetuar nenhuma medição e contrariamente ao testemunho unânime dos pilotos e aos protestos do representante da casa de Vimieiro, mandou estabelecer a fronteira por uma pedra natural que ele indicou, na barra mais ao sul, deixando acima a vila de São Vicente. Em função disso, com extrema injustiça, a condessa de Vimieiro viu-se despojada da Capitania de São Vicente e transferiu a sede de seus domínios para a Vila de Itanhaém (1624), continuando sua jurisdição sobre as cidades daí para o sul e no Vale do Paraíba, São Sebastião, Paraty, Angra dos Reis, Rio de Janeiro e Cabo Frio. 
6 Tentativas de demarcação das linhas divisórias?

Procurando algum paralelismo de linhas geométricas demarcando territórios, vêm imediatamente à lembrança as divisões do Canadá e principalmente dos Estados Unidos. Efetivamente, houve certa semelhança com as divisas de nossas capitanias, sendo emblemática a repartição entre Pennsylvania e Maryland, cujos limites geométricos foram definidos nas cartas de doação a William Penn e Lord Baltimore, por volta de 1640.

A carta de doação do primeiro território previa o paralelo correndo 15 milhas ao sul de Filadélfia, e a do segundo o paralelo $40^{\circ}$. Acresciam-se mais condições pela carta de doação do Delaware: um termo de 12 léguas para a cidade de New Castle e uma tangente a esse círculo, tirada pelo ponto médio da península desse Estado. Isso poderia gerar uma superposição de territórios e um enorme problema geométrico para a época, que só foi resolvido graças à perícia de dois dos maiores astrônomos/geodesistas da Inglaterra (Mason e Dixon). A implantação e a demarcação da mesma sobre o terreno foram bastante demoradas (1758-1760). ${ }^{25}$

Nessa época já se contava com equipamentos de campo, para medir azimutes e calcular coordenadas (latitude e longitude). No tempo de nossas capitanias, 100 anos antes, a tarefa era impraticável, pelas condições naturais (serras, montanhas e mata fechada), aliada à falta de equipamentos e técnicos. Mas não faltou quem indicasse a demarcação das linhas a noroeste do lote setentrional de Martim Afonso.

De fato, houve dois momentos na questão Monsanto-Vimieiro em que se apontava para isso. A Relação da Bahia indicou, em 6 de novembro de 1623, que se demarcassem as 50 léguas de Pero Lopes de Sousa. ${ }^{26}$ Essa ordem não deu em nada, pois como se apontou, o procurador da Fazenda simplesmente estabeleceu uma pedra natural como divisa. Em outra oportunidade (171 1), por ocasião da compra da Capitania de Santo Amaro por parte da Coroa, também se indicou fazer a medição e demarcação, implantando-se os marcos necessários entre essa e a de São Vicente. Mas os camaristas de São Paulo, em vez de fazerem as medições, simplesmente declararam que a essa capitania pertencia tudo: Santos, São Paulo, São Vicente e todas as que dela dependiam. ${ }^{27}$

7 Edificando vilas em território alheio: os limites de São Vicente e Santo Amaro no sertão

A Figura 5 mostra com mais detalhes os limites dessas duas capitanias, e sobre esse mapa inserimos as cidades e vilas (1532-1700) compreendidas nessas terras (ver Tabela 1).

Como já se apontou, o assentamento do Rio de Janeiro e de Cabo Frio em terreno alheio foi aceito e tolerado pela Coroa e serviu como ponta de lança
22. Leme (2004, p. 119).

23. Cintra (2013).

24. Veja-se, a esse propósito, Madre de Deus (1780, p. 6567; 1975, p. 203-205).

25. Para essa questão, vejase Danson (2001).

26. Mandava "que o Provedor da Fazenda da Capitania de São Vicente com 4 ou 5 pilotos (...) demarque e meça as 50 léguas (...) pondo padrões nos lugares assinalados na Doação (...) e lançando as 
para a ocupação e usurpação do lote setentrional da Capitania de São Vicente. As demais vilas nesse lote foram criadas pelo donatário (sucessores de Martim Afonso). As vilas na costa, ao sul, de Santos a Cananeia, também foram criadas em território de Martim Afonso, em seu lote meridional.

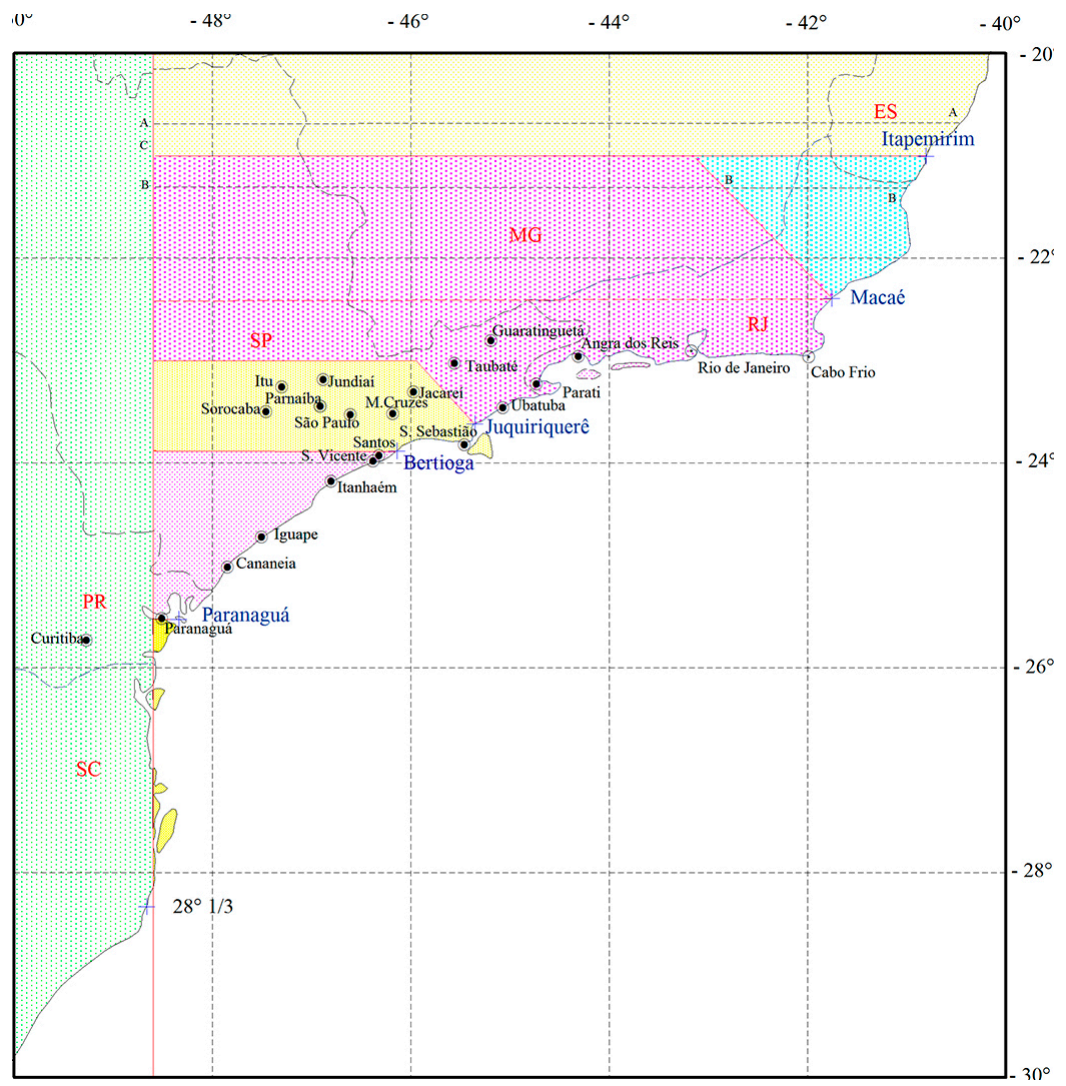

Figura 5 - Vilas e cidades em terras alheias (1532-1700). Fonte: o autor.

Mas o que mais chama a atenção nesse mapa é a enorme quantidade de vilas surgidas a partir de São Vicente, construídas nas capitanias de Pero Lopes de Sousa: Paranaguá está quase sobre a linha divisória, mas em sentido estrito já está na Capitania de Santana; Curitiba, no sertão e fundos de Paranaguá, foi a primeira vila criada em terras de Castela.

E na Capitania de Santo Amaro, tem-se: São Paulo (nada menos), Santana de Parnaíba, Sorocaba, Itu, Jundiaí, Jacareí, Mogi das Cruzes e São Sebastião. Ou seja, todas essas vilas, tidas como pertencentes ao lote sul de Martim Afonso, Capitania de São Vicente de que dependiam, na realidade foram implantadas na Capitania de Santo Amaro. $O$ Conde de Monsanto e seus representantes não precisariam ter recorrido ao expediente de contrariar o testemunho unânime dos pilotos, forçar a implantação de um marco na barra sul de São Vicente e todas as tropelias que fizeram. Bastaria ter procedido à demarcação de acordo com as cartas de doação para obter a posse dessas vilas. Só ficariam de fora Santos e São Vicente. 
A pergunta imediata é: será que ninguém se deu conta disso na época da fundação das vilas; durante as discussões em torno da questão MonsantoVimieiro (que durou até finais do dezessete); ou no tempo de Pedro Taques e Frei Gaspar $^{28}$ (dezoito)? A cláusula das linhas correndo a noroeste foi, sim, aventada na questão de Monsanto-Vimiero, como o demonstram os textos anteriormente citados, transcritos por ocasião da indicação de lançar as linhas no terreno; também o foram pelos dois primeiros historiadores de São Paulo, já que copiaram mais de uma vez as cartas de doação. No dezenove, Varnhagen leu as léguas, mas não as linhas a noroeste; e também não houve tentativas de posicionar as vilas com relação a elas, quaisquer que fossem as direções.

Essa despreocupação de lançar as linhas, a despeito da falta de tecnologia ou do que se queira argumentar, talvez se deva a outro motivo, mais relacionado ao conceito de território, jurisdição e outros, para designar as terras dependentes de uma vila e de uma capitania, na época em questão (1 500-1700).

8 Os conceitos de território, costa, sertão, termo e o imaginário da época

Esse aparente paradoxo ou choque cognitivo, de construir vilas em terras alheias, visível na Figura 5, pode ser desfeito considerando a diferença de imaginários entre essa época e a nossa.

Nos últimos anos, assistimos a um renovado interesse pelo estudo das fronteiras. Langfur 29 faz uma ampla análise dos diversos termos utilizados na historiografia e relaciona a noção de fronteira, que nos interessa mais de perto, com a bandeira e o sertão. Outros consideram esse conceito não tanto como linhas demarcadas, mas como um espaço em construção, muitas vezes indefinido e em expansão, caracterizando o choque entre os autóctones e o colonizador, como destaca Herzog. ${ }^{30}$ Mandrini $^{31}$ acrescenta o matiz da construção do poder associada ao território e o caracteriza como o limite da terra adentro e o confuso mundo da civilização. Ortelli32 e Gascón ${ }^{33}$ destacam que a historiografia enfatizou muito a perspectiva da guerra e do enfrentamento, deixando de analisar outras variáveis sociais. No presente artigo, não tratamos tanto da fronteira entre lusobrasileiros e hispânicos ou em direção a terras indígenas, mas sim de outro fator social importante, a jurisdição das vilas e daquela que era considerada cabeça da capitania, em contraposição com as linhas teóricas definidas nas cartas de doação. Fazemos isso olhando para os textos de época.

Para isso, começamos a análise pelo que se entendia por terras ou território de uma capitania. Como destaca Bueno, ${ }^{34}$ território, com contornos precisos e definidos, é uma categoria histórica, socialmente construída, e seria própria do XVIII, e assim não se aplicaria às capitanias hereditárias nem aos mapas que as representam.

Em contraposição, num primeiro olhar para o mapa de Luis Teixeira (de fins do XVI) e para os mapas das capitanias, inclusive o da Figura 1, notamos que linhas pelos rumos declarados nela..." e verificasse em que terras ficavam as vilas em disputa. Madre de Deus (1780, p. 109; 1975, p. 199).

27. Leme (2004, p. 117).

28. Frei Gaspar, em certo momento, queixa-se de que "ninguém leu a carta de doação [de Martim Afonso] (...) e se não a viram, que assenso merecem quando assignam [indicam] as confrontações?". Madre de Deus (1780, p. 71).

29. Langfur (2014). 
30. Herzog (2015).

31. Mandrini (2006).

32. Ortelli (2011).

33. Gascón (2011).

34. Bueno (2009).

35. Somando-se a isso os conceitos de domínio e jurisdição, associados a esses territórios, aparecem de maneira clara nos textos fundantes: forais e cartas de doação.

36. Carta enviada a Martim Afonso de Sousa, de 28/9/1532, estando este ainda no Brasil. Madre de Deus (1975, p. 94-100).

37. Aliás, havia restrições para as entradas no sertão e o incentivo para a ocupação da costa, para não dispersar esforços e garantir a segurança das vilas, em função dos ataques indígenas. Assim se entende melhor a proibição de Martim Afonso de subir a serra e entrar no sertão.

38. Existe, sim, em algumas delas, a indicação de colocar marcos e, em algumas do sul, a de lançar as linhas, mais como uma definição para traçar abstrata e geometricamente no e para o papel do que uma ordem de implantar diretrizes no terreno, coisa que nunca se fez.

39. Expressão que corresponde a meus domínios (senhorio), pois na América não houve conquista propriamente dita, mas um tratado de divisão com a Espanha, não reconhecido por outros países. elas possuem contornos precisos e definidos: pontos demarcados na costa e linhas que correm em direções conhecidas e se limitam a oeste pela Linha de Tordesilhas. ${ }^{35}$

Mas, analisando com maior profundidade, os conceitos que na prática predominavam na época não eram os de um território fechado por contornos e fronteiras precisas. Não foi esse imaginário que gerou a expansão ou a ocupação do espaço. Outros foram os conceitos fortes, que aparecem explicitamente nos documentos da época e permeiam as delimitações do espaço: terras, costa, sertão, fundos e termo.

Terras e Terras do Brasil são termos frequentes, mas o primeiro que salta à vista e difere do nosso conceito é o de costa. Assim, na carta em que comunica a Martim Afonso sua decisão de distribuir terras, ${ }^{36}$ D. João III fala da Costa brasileira (sempre com maiúscula) e não de territórios circunscritos por limites geográficos. Outras expressões que aparecem nos textos da Coroa são: "Costa e terra do Brasil"; "80 léguas de terra da dita Costa do Brasil"; "Capitania de São Vicente, Costa do Brasil"; "determinei de mandar demarcar ... cinquenta léguas de Costa a cada Capitania ... e assim se dará a maior parte da Costa". É de se notar que as léguas são uma medida linear, de distância e comprimento e não de área. Em outros momentos, o aparente paradoxo aumenta quando se fala, por exemplo, em demarcar as 50 léguas para ver que vilas e povoações se situavam dentro delas. Ora, as vilas não podem ficar dentro de uma linha e, portanto, deve-se supor que às léguas na costa estão associadas terras no interior; essa expressão denota, portanto, não só a costa, mas as terras, o espaço geográfico. ${ }^{37}$ De fato, também se encontram expressões mais precisas como: "Todas as povoações que estiverem pelo sertão e pela costa, dentro das 50 léguas". É como se as léguas resumissem todo o território, costa e sertão.

Nesse sentido, a própria carta de doação esclarece dizendo que essas léguas "se estenderão e serão de largo ao longo da costa, e entrarão pelo sertão e terra firme adentro, tanto quanto puderem entrar e forem de minha conquista".

Aparecem aí outros dois novos conceitos ou expressões recorrentes: o primeiro, sertão, bastante indefinido, representando regiões afastadas da marinha, cujos confins não são delimitados, estando ainda por dilatar. $\bigcirc$ segundo, terra firme, contraposto ao conceito de ilha, que faz parte de um imaginário que vem das descobertas ou redescobertas das ithas do Atlântico (Açores, Madeira, Canárias, Cabo Verde etc.). As expressões multiplicam-se, muitas vezes associadas a outros conceitos: "Terra firme adentro"; "com todos os seus fundos (nova expressão) em terra firme"; "50 léguas e seus fundos"; "ambas as llhas e seus fundos e sertões"; "as vilas situadas em seus fundos" e outros exemplos semelhantes.

Nos forais e cartas de doação, não existe a preocupação de demarcar e definir regiões fechadas. ${ }^{38} \mathrm{~A}$ indicação de linhas correndo para oeste só ocorre em duas delas, e também não há uma referência direta à Linha de Tordesilhas; a delimitação é feita, como já se transcreveu acima, pela expressão: "e entrarão pelo sertão adentro, quanto puder entrar e for de minha conquista". 39

Assim, o conceito-chave para entender a construção do espaço geográfico das capitanias não foi o de um território, uma região fechada definida 
pelas cartas de doação. Foram os acima apresentados e, mais do que eles, o conceito de termo das vilas. A capitania se define territorialmente não pela geometria de um polígono, mas por uma linha na costa onde se criavam vilas, às quais se associavam os seus fundos e sertões, áreas agregadas que vão ser definidas e ampliadas pelos termos das novas vilas criadas na dependência jurisdicional das anteriores, em sucessivas levas.

Criava-se uma vila (ou cidade) e definia-se o seu termo, conceito-chave, que equivale a uma área ou região à sua volta, à qual se estendia sua jurisdição. Para a definição desses limites a distância costumeira era de 6 léguas em quadra. Não são seis léguas quadradas nem um quadrado com lado de 6 léguas; essa expressão equivale a estabelecer uma distância de 6 léguas (36 quilômetros aproximadamente) em todas as direções, ou seja, teoricamente um círculo com raio de 6 léguas; na prática 6 léguas medidas ao longo de cada caminho que saía dessa vila. Com peculiaridades, pois nas cidades costeiras, com as barreiras do mar e das montanhas, seriam 12 léguas na costa, com a vila ao meio e um terreno até o sopé ou a crista das montanhas.

Esse valor de 6 léguas foi definido também nas cidades de Salvador e Rio de Janeiro. Mas havia outros valores. No sertão, a distância mínima entre duas vilas deveria ser de 6 léguas, para conseguir um termo de três léguas para cada uma. Na costa, Santos e São Vicente representam uma exceção motivada pelo crescimento de Santos (um porto de condições excepcionais) e por não se querer transferir o pelourinho de São Vicente para lá, por ser a sede da capitania e a mais antiga vila do Brasil. Mas eram comuns valores maiores, estabelecidos de maneira mais ou menos arbitrária, como em Cabo Frio, cujos termos iam até o limite da capitania, ao norte; e ao sul, até encontrar os primeiros moradores do Rio de Janeiro.

Além disso, uma vez fundada uma vila, reservavam-se umas terras mais próximas para o terreno urbano, o rocio, que costumava ser de légua e meia, cujas terras, não pertencentes anteriormente a particulares, poderiam ser distribuídas ou arrendadas pela Câmara. Dentro dele, de fato, distribuíam-se chãos e datas, terrenos de dimensões relativamente pequenas, não mais que uma chácara. No termo e fora do rocio distribuíam-se sesmarias, que podiam variar de uma a várias léguas em quadra, ou seja, latifúndios, cujos limites em geral eram bastante imprecisos. Os ocupantes, oriundos e muitas vezes moradores na vila, começavam a ocupar essas sesmarias e estavam ligadas a ela: eram moradores dos seus termos e dela dependentes para efeitos não só de comércio, assistência espiritual, mas também de jurisdição nos diversos âmbitos. Com o passar do tempo, uma vez distribuídas as terras mais próximas, as sesmarias iam-se situando em pontos cada vez mais afastados e, mais adiante, os núcleos podiam desenvolver-se até ganhar independência, sendo então elevada à categoria de vila. Por exemplo, São Sebastião, que se situava na Capitania de Santo Amaro, a mais de $100 \mathrm{~km}$ de Santos pela costa, foi desmembrada de Santos. No auto de sua criação lê-se: "nesta povoação de São Sebastião da terra firme [para distinguir da itha de mesmo nome], Termo e Jurisdição da Vila de Santos, da Capitania de São Vicente". Ou 
40. Um interessante diagrama poderia ser montado: um mapa com as vilas de nossos dois primeiros séculos, incluindo setas que, partindo da cidade-mãe, as ligasse a aquelas que se desmembraram a partir dela. Isso mostraria, mais do que uma rede de cidades (todas unidas a todas), um esquema de dependência com nós, sendo São Paulo, sem dúvida, um deles.

41. Por reconhecer alguma existência de terras que não eram suas, mas dos herdeiros de Martim Afonso, não reivindicou Itanhaém, Iguape e Cananeia, mas criou uma nova capitania, a de Paranaguá, com sede nessa vila, que incluiria em seus domínios ou termo todas as cidades ao sul, até Laguna. De fato, encontravam-se nas Terras de Santana, que pertenciam a Pero Lopes de Sousa, de quem por complexos caminhos herdou a capitania. seja, a origem dos moradores, certa proximidade e a dependência econômica ou social contaram mais do que o território definido na carta de doação.

Em resumo, cada povoação dependia da vila mais próxima, de onde haviam saído seus moradores para cultivar as terras recebidas em sesmaria. Uma vez criada, a nova vila deixava de depender da vila originária e passava a reportar-se diretamente à cabeça da capitania. Assim ia-se estendendo o território da capitania, sem importar-se com uns limites geométricos fechados, não demarcados.

Vale acrescentar que a transformação de povoação (mais tarde freguesias e distritos) era de certa forma traumática para a vila originária: havia que repartir com ela o termo, fixar os limites entre uma e outra e deixava-se de poder ocupar o território e distribuir sesmaria nessa direção.

Assim, pode-se notar o crescimento de São Vicente para o sul, criandose as diversas vilas pela costa: Itanhaém, Iguape, Cananeia, Paranaguá. A cidade mais ao sul ficava com termo limitado ao norte, mas indefinido ao sul e a oeste. Assim, vemos surgir São Francisco, Laguna e Desterro, bem como Curitiba no interior.

No litoral norte, a mesma coisa: Santos, São Sebastião, Ubatuba, Angra e Paraty (por desmembramento da anterior) e também no Vale do Paraíba: Taubaté, Guaratinguetá, Jacareí. No planalto, ocorre o mesmo fenômeno: São Paulo gerando Mogi das Cruzes, Jundiaí e Santana de Parnaíba; e esta originando Sorocaba e ltu. 40

Em nenhum momento se faz referência à localização no território da capitania para atribuir a uma vila sua pertença a determinado donatário. $\mathrm{Na}$ famosa controvérsia entre as casas de Monsanto (Capitania de Santo Amaro) e Vimieiro (Capitania de São Vicente), como dissemos, bastaria ao Conde de Monsanto recorrer ao argumento cartográfico (demarcar ou desenhar as linhas num mapa como o da Figura 5) para mostrar quais vilas the pertenciam, que eram quase todas. No entanto, não o fez, mas recorreu à força e ao despotismo de seus representantes para deslocar o marco divisório, na costa, para o braço de mar abaixo de São Vicente. Possuindo a cabeça da capitania, possuía todas as vilas nascidas direta ou indiretamente em seus termos. ${ }^{41}$

Aconteceu assim um paradoxo: a Capitania de Santo Amaro, aparentemente pequena ( 10 léguas na costa), que nunca teve vila criada por Pero Lopes ou seus descendentes, com o atropelo da justiça e usurpação de terras da Capitania de São Vicente, ficou com uma grande parcela de todas as vilas criadas por Martim Afonso e seus sucessores. A Condessa de Vimieiro, descendente desse donatário, transferiu a sede para Itanhaém e ficou com mais duas vilas ao sul (lguape e Cananeia) e outras no vale do Paraíba: Taubaté e Guaratinguetá, tendo sido criadas, em seu tempo ou de seus descendentes, outras vilas, como Pindamonhangaba e São José dos Campos. Ubatuba foi criada na dependência desse governo, que também continuou com a jurisdição parcial sobre Paraty e Angra dos Reis, e sobre as terras de Cabo Frio e Rio de Janeiro. 


\section{Considerações finais}

Ao nos aprofundarmos no estudo do novo mapa das capitanias hereditárias, mostramos uma série de conflitos na definição dos limites entre elas. Conflitos que, geometricamente falando, ocorrem mais na teoria do que na prática, porque não houve sequer tentativas de demarcar as terras no sertão. Os conflitos ocorrem mais por atropelo da justiça do que por interpretação dos limites definidos nas cartas de doação. A história dos confins permitiu entender melhor as fronteiras dos atuais estados e possibilitou compreender melhor o imaginário da época em contraposição ao nosso, no tocante à definição do espaço geográfico, destacando as noções de sertões, fundos e principalmente termo de uma vila, o que foi determinante para definir a expansão e formação dos atuais territórios. Os territórios ou espaços delimitados com que se procura representar as capitanias talvez existam mais no nosso imaginário do que no das pessoas da época. 


\section{REFERÊNCIAS}

BUENO, Beatriz Piccolotto Siqueira. Dilatação dos confins: caminhos, vilas e cidades na formação da Capitania de São Paulo (1532-1822). Anais do Museu Paulista: História e Cultura Material, São Paulo: Museu Paulista, v. 17, n. 2, p. 251-294, jul.-dez. 2009.

CINTRA, Jorge Pimentel. As capitanias hereditárias no mapa de Luís Teixeira. Anais do Museu Paulista: História e Cultura material, São Paulo: Museu Paulista, v. 23, n. 2, p. 11-42, dez. 2015.

A formação do território da capitania do Rio de Janeiro. Acervo, Rio de Janeiro: Arquivo Nacional, v. 29, n. 1, p. 67-81, jan.-jun. 2016.

O mapa das cortes e as fronteiras do Brasil. Boletim de Ciências Geodésicas, Curitiba: Programa de Pós-Graduação em Ciências Geodésicas da UFPR, v. 18, n. 3, p. 421-445, 2012. Disponível em: <http://revistas.ufpr.br/bcg/article/view/29209/19006>. Acesso em: 2 jun. 2017.

Reconstruindo o Mapa das Capitanias Hereditárias. Anais do Museu Paulista, São Paulo: Museu Paulista, v. 21, n. 2, p. 11-45, jul.-dez. 2013.

DANSON, Edwin. Drawing the Line: How Mason and Dixon Surveyed the Most Famous Border in America. New York: Wiley, 2001.

GASCÓN, Margarita. Periferias imperiales y fronteras coloniales en Hispanoamérica. Buenos Aires: Editorial Dunken, 2011.

HERZOG, Tamar. Frontiers of Possession: Spain and Portugal in Europe and Americas. Cambridge (USA): Harvard University Press, 2015.

LAMEGO, Alberto. Mentiras históricas. Rio de Janeiro: Record, [s.d].

LANGFUR, Hal. Frontier/Fronteira: A Transnational Reframing of Brazil's Inland Colonization. History Compass, Medford (USA): Wiley, v. 12, issue 11, p. 843-852, nov. 2014. Disponível em: <http://onlinelibrary.wiley.com/doi/10.1111/hic3.12200/full>. Acesso em: 2 jun. 2017.

LEME, Pedro Taques de Almeida Pais. História da capitania de São Vicente. Brasília: Senado Federal, 2004. Original de 1772. Disponível em: <http://www2.senado.leg.br/bdsf/bitstream/ handle/id/1087/690140.pdf?sequence=4>. Acesso em: 2 jun. 2017.

MACHADO JUNIOR, Armando Marcondes. Divisão territorial do Estado de São Paulo: Resgate histórico. 4. ed. São Paulo: Mageart, 2011.

MADRE DE DEUS, Frei Gaspar da. Dissertação sobre as capitanias de Santo Amaro e São Vicente. Mosteiro de São Bento da Vila de Santos, 30 nov. 1780. Biblioteca Nacional de Lisboa, Cód. 11.107, F.R. 1284. Edição filológica: Patrícia Simone Ferucio Manoel. Revisão: Priscilla Uvo Moraes.

Memórias para a história da capitania de São Vicente. São Paulo: Edusp, 1975. 
MANDRINI, Raúl José. Vivir entre dos mundos: las fronteras del sur de la Argentina, siglos XVIII y XIX. Buenos Aires: Taurus, 2006.

ORTELLI, Sara. Representaciones en torno al territorio y las relaciones sociales en las fronteras iberoamericanas, siglos XVIII y XIX. Antíteses, Londrina: Departamento de História da UEL, v. 4, n. 8, p. 427-431, jul.-dez. 2011. Disponível em: <http://www.uel.br/revistas/uel/index.php/ antiteses/article/view/10855/11080>. Acesso em 2 jun. 2017.

VARNHAGEN, Francisco Adolfo de. História geral do Brasil. 5. ed. São Paulo: Melhoramentos, $1956.5 \mathrm{v}$. 